\title{
ANÁlise EVOLUTIVA SÓCIO PRODUTIVA DE ALIMENTOS NA AGRICULTURA FAMILIAR NO MUNICÍPIO DE CRISSIUMAL-RS
}

\author{
Eduardo Canepelle ${ }^{1}$, Jocieli Caroline Steinhaus ${ }^{1}$, Patricia Inês Kemper Back ${ }^{1}$, Luciane Sippert², Danni \\ Maisa da Silva ${ }^{2}$, Marciel Redin², Robson Evaldo Gehelen Bohrer ${ }^{2}$, Divanilde Guerra ${ }^{2}$
}

\begin{abstract}
RESUMO - A agricultura familiar é considerada a base da produção de diversos alimentos. Porém, nos sistemas de produção atuais, muitas alterações sócias produtivas estão ocorrendo, levando à redução de áreas de plantio para subsistência familiar e a perdas de diversidade de culturas. Desta forma, objetivo do presente trabalho foi avaliar as mudanças ocorridas na população e produção de alimentos na agricultura familiar do município de Crissiumal ao longo dos últimos anos. A metodologia utilizada para a realização do trabalho consistiu em pesquisa de campo com moradores dos distritos do Município, bem como com entidades públicas que trabalham diretamente com o setor agrícola. Como resultados, observou-se uma redução drástica na população do meio rural, bem como na área destinada à produção de alimentos de subsistência, de aproximadamente 1,5 a 10 hectares para áreas inferiores a 0,5 hectare. Além disso, observou-se uma redução considerável no número de espécies cultivadas, pois antigamente os principais cultivos para o consumo familiar eram: feijão, batata-doce, batata inglesa, cebola, amendoim, dentre outros; atualmente, são produzidos apenas alimentos de consumo primário, como hortaliças, mandioca e batatadoce e, como consequência disso, pode-se constatar alterações nos hábitos alimentares, devido à dependência de alimentos processados. Portanto, contata-se redução considerável a partir da revolução verde na população do meio rural, área e na diversidade de produção de alimentos pelos agricultores do município de Crissiumal.
\end{abstract}

Palavras chave: agricultura familiar, erosão alimentar, êxodo rural.

\section{EVOLUTIVE ANALYSIS FOOD PRODUCTIVE PART IN FAMILY FARMING IN CRISSIUMAL-RS MUNICIPALITY}

\begin{abstract}
Family farming is considered the basis of the production of various foods. However, in today's production systems many socio-productive changes are occurring, leading to the reduction of planting areas for family subsistence and loss of crop diversity. In this way, the objective of the present work was to evaluate the changes occurred in the population and food production in the family agriculture of the municipality of Crissiumal over the last years. The methodology used to carry out the work consisted of field research with residents of the districts of the Municipality, as well as with public entities that work directly with the agricultural sector. As a result, there was a drastic reduction in the rural population as well as in the area destined to the production of subsistence foods, of approximately 1.5 to 10 hectares for areas smaller than 0.5 hectare. In addition, there was a considerable reduction in the number of cultivated species, since in the past the main crops for family consumption were: beans, sweet potatoes, English potatoes, onions, peanuts, among others; currently, only primary foodstuffs such as vegetables, manioc and sweet potatoes are produced and, as a consequence, changes in eating habits can be observed due to the dependence of processed foods. So, do you contact considerable reduction from the green revolution? in the rural population, area and in the diversity of food production by the farmers of the municipality of Crissiumal.
\end{abstract}

Keywords: family farming, food erosion, rural exodus.

\footnotetext{
${ }^{1}$ Academicos do Curso de Bacharelado em Agronomia. Universidade Estadual do Rio Grande do Sul - UERGS. Unidade em Três Passos, Rua Cipriano Barata, 211 - Bairro Érico Veríssimo, Três Passos. CEP: 98600-000. Contato (55) $3522-2895$. E-mails: eduardocanepelle@gmail.com; jocielisteinhaus@yahoo.com.br; patriciaback16@gmail.com

${ }^{2}$ Docentes da Universidade Estadual do Rio Grande do Sul - UERGS. Unidade em Três Passos, Rua Cipriano Barata, 211 - Bairro Érico Veríssimo - Três Passos. CEP: 98600-000. Contato (55 )3522-2895. E-mails: lucianesippert@uergs.edu.br; danni-silva@uergs.edu.br; marcielredin@gmail.com.br; robson-bohrer@urros.edu.br; divanilde-guerra@uergs.edu.br.
} 


\section{INTRODUÇÃO}

O município de Crissiumal é reconhecido como a terra das agroindústrias familiares, pois boa parte dos produtos obtidos pela agricultura familiar são industrializados nas propriedades rurais. Este está localizado na região Noroeste do Rio Grande do Sul,

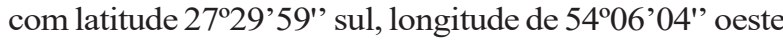
e altitude de 402 metros. Sua população em 2016 era de aproximadamente 14.233 habitante em uma área de $363,106 \mathrm{~km}^{2}$. O nome do município teve sua origem na vegetação denominada criciúma (Arundinaria aristulata), a qual é encontrada em grandes proporções nas matas da região (Schwanke \& Polh, 2007). A sua fundação foi em 1933, embora a emancipação oficial tenha vindo somente em 1954. Segundo Schwanke \& Pohl (2007), a ocupação humana, inicialmente, deuse com indígenas. Isto pode ser comprovado pelos vestígios encontrados por agricultores em várias localidades do município, tais como vasos de cerâmica e boleadeiras.

Com relação a colonização, destaca-se que os primeiros imigrantes que chegaram ao município eram agricultores familiares e vieram em busca de terras mais férteis para o desenvolvimento da agricultura (Schwanke \& Pohl, 2007). Atualmente, a região Noroeste do RS caracteriza-se por ser uma região essencialmente agrícola e com um grande número de pequenos estabelecimentos rurais (Trennepohl \& Macagnan, 2008). Segundo Castro (2001), os principais cultivos agrícolas na região são para a subsistência familiar e venda do excesso da produção. A região também possui atividades nas áreas de suinocultura e bovinocultura de leite, sendo que todos estes sistemas de produção estão baseados na propriedade rural familiar.

O município apresenta um grande número de produtores rurais, dentre os quais a mão de obra familiar é predominante. Estes se dedicam à produção de alimentos, porém nos últimos anos, este sistema vem sofrendo mudanças significativas se direcionando para o cultivo de poucas culturas, principalmente com foco comercial. Esta informação corrobora com dados em nível nacional, pois segundo Schwanke \& Pohl (2007), o Brasil, após a década de 60 marcou sua história pela política agrícola voltada para a monocultura. Neste contexto, Crissiumal caracterizado por pequenas propriedades familiares sentiu os reflexos dessa política e priorizou os cultivos de trigo, e especialmente de soja. Esse modelo trouxe graves consequências sociais e econômicas em todo o Brasil, além do êxodo rural, aumentou a fome e consequentemente o inchaço das cidades (Schwanke \& Pohl, 2007). Devido à diminuição do número de famílias na agricultura, as atividades das propriedades foram direcionadas para o cultivo de poucas espécies, levando a perda da diversidade. Neste contexto, o objetivo do presente trabalho foi avaliar nas últimas décadas as mudanças ocorridas na população e produção de alimentos na agricultura familiar do município de Crissiumal.

\section{MATERIAL E MÉTODOS}

A metodologia utilizada para a realização do trabalho consistiu em pesquisa de campo, realizada no município de Crissiumal - RS, o qual foi dividido em quatro distritos, além da sede: Esquina Gaúcha, Lajeado Grande, Vila Planalto e Vista Nova.

A pesquisa contou com a participação de cinco entrevistados, um de cada distrito do município, sendo três do sexo masculino e dois do sexo feminino. A faixa etária de idade das pessoas entrevistadas variou de 47 a 83 anos. Para cada entrevistado foi aplicado um formulário com perguntas sobre: Quais foram os motivos para vir residir no município? Qual era o manejo adotado quando chegaram no município? Quais as principais culturas cultivadas para a produção de alimentos e sua origem? Qual a área destinada a produção de alimentos para subsistência no passado e atualmente? A mudança ocorrida na produção de alimentos nos últimos anos interferiu nos hábitos alimentares? Além disso, procedeu-se uma entrevista com agentes públicos que trabalham diretamente com a agricultura, ou seja, o secretário de agricultura do município e o técnico agrícola, além do chefe do escritório municipal da EMATER-RS. Aos quais foram levantadas perguntas relacionadas sobre quais foram os principais motivos que levaram a essa mudança drástica dos hábitos alimentares das comunidades rurais do município. Após realização das entrevistas, as informações foram analisadas sendo que as obtidas nas propriedades foram comparadas entre si, para assim, realizar a descrição e estudo das propriedades para partir daí fazer descrição dos resultados das propriedades estudas, seguindo a mesma temática as informações coletadas em ambas as instituições públicas foram comparadas entre si para então poder realizar a discrição dos resultados. 


\section{RESULTADOS E DISCUSSÃO}

Atualmente, a principal fonte de renda do município de Crissiumal provém da produção e extração animal e vegetal, representando $58,2 \%$, da renda total do município em 2015. Desta forma, a maior parte do PIB municipal (Produto Interno Bruto) provem da agricultura. A economia está baseada nas pequenas propriedades rurais. A economia está baseada nas pequenas propriedades rurais, as quais se dedicam às mais variadas atividades agrícolas, como: bovinocultura de leite, suinocultura integrada, cultivos de comodites agrícolas, plantio do fumo, além das agroindústrias familiares que se dedicam à industrialização de vários produtos.

\section{Moradores locais}

Nas entrevistas realizadas com os moradores foram analisados o motivo pelo qual vieram residir, o manejo adotado na produção de alimentos, as culturas que eram cultivadas quando chegaram ao município, o tamanho da área destinada para produção de alimentos para subsistência familiar no passado e atualmente, as mudanças nos hábitos alimentares das pessoas residentes ao longo do tempo e quais as principais culturas cultivadas para consumo familiar atualmente.

Como resultados, observou-se que a maioria das pessoas entrevistadas é de descendência alemã ou italiana e vieram residir no município em busca de terras mais férteis, uma vez que o local das colônias velhas (Estrela, Lajeado e Sobradinho) encontravam-se com alta densidade populacional. Os novos moradores vieram para o município, em sua maioria, de caminhão, demandando em torno de três dias para chegar ao destino. Segundo relato de um entrevistado outros imigrantes de municípios vizinhos, como Horizontina, vieram de carroça as quais eram puxadas por cavalos. Ainda, de acordo com Schwanke \& Pohl (2007), as mudanças eram transportadas em caminhões, carroças, cavalos e ônibus.

Conforme o relato dos entrevistados, quando estes chegaram nas localidades, não haviam escolas, o comércio era restrito e apenas em algumas comunidades havia igrejas. De acordo com levantamentos históricos de Pletsch (1977), o qual descreveu o cenário de Crissiumal no início de sua colonização, com ajuda de uma moradora, não havia escola, nem médico, nem parteira, além disso, salientam que as feras do mato rondavam as residências. Era difícil a colocação dos produtos agrícolas no mercado consumidor, pois só conseguiam vender banha e ovos. Também era precário o abastecimento de gêneros alimentícios, fato este que se finda com a abertura da primeira casa comercial.

No tocante à produção e ao manejo de solo e plantas adotado no início, predominava a derrubada de mato com auxílio de serrotes ou machados, após este era queimado. Nos primeiros dois anos a lavoura era apenas preparada com o auxílio de enxadas, pois era impossível lavrar devido à grande quantidade de tocos e raízes. Após este período dava-se início ao preparo das terras com arado, o qual era puxado por tração animal. Machado (2001) realizou levantamento histórico dos sistemas agrários existentes no município de Crissiumal e afirma, que os imigrantes encontravam uma área com densa vegetação e, portanto, para cultivá-la, utilizam uma adaptação da técnica indígena em sistema conhecido como coivara, onde era derrubada a vegetação com o auxílio de foice, machado e serrotes. Após a queima do material sobre o solo, era feita a semeadura, principalmente de milho e feijão ou plantio de ramas de mandioca com o auxílio de paus ou saraquás. Segundo Oliveira (1989), as principais operações de artificialização do meio florestal para a prática de agricultura são a derrubada e a queimada.

Naquele período, entre décadas de 50 e 80 , as principais espécies cultivadas eram: milho, arroz sequeiro, feijão, mandioca, batata inglesa, batata-doce, melancia, hortaliças em geral, cana de açúcar, amendoim, cebola, soja, trigo, entre outras. Na maioria dos casos as sementes e mudas utilizadas foram trazidas dos locais de origem ou adquiridas com moradores que já residiam na região. Dentre as sementes trazidas destacam-se: milho, feijão e arroz; e as principais mudas trazidas foram: cana de açúcar, batata doce e banana. Também havia a troca de sementes e mudas entre vizinhos e familiares como por exemplo a mandioca, para evitar o plantio da mesma variedade ao longo dos anos. Além disso, era muito utilizado o cultivo consorciado de espécies como a soja e o milho, as quais se destinavam a alimentação humana e dos animais lavagem para os porcos, produzindo assim o porco "tipo banha" o qual era a principal fonte de comercialização das propriedades na época. Schallenberger \& Hartmann afirmam que: 
Os animais eram fechados em currais e chiqueiros que normalmente não obedeciam a nenhum critério de higiene e salubridade. Eram tratados com produtos da própria lavoura, natural. A lavagem, espécie de ensopado feito com a mistura de abóbora, batata-doce ou mandioca e soja, constituiuse em um dos alimentos básicos para a suinocultura. Apesar da técnica rudimentar empregada para criação dos porcos, os agricultores tiveram nesta atividade econômica uma boa fonte de renda. Depois de engordados, eles entregavam os animais para o mercado, sem investimentos extra propriedade. $\mathrm{O}$ único produto complementar que se fazia necessário adquirir era o sal (Schallenberger \& Hartmann, 1981, p.125).

Ainda, segundo Machado (2001), no sistema agrário colonial desenvolvido de 1930 até 1970 , era também muito realizado o consórcio de milho e feijão e também de abóbora com milho e mandioca. Com esse manejo os agricultores desenvolviam rotação de culturas e ajudavam na melhoria da fertilidade do solo. Contudo, este sistema de produção perdeu espaço ao longo das décadas.

Segundo Presser (1978), a suinocultura, que era o principal produto comercial dos colonos das regiões de colonização, perdeu seu dinamismo, ou seja, foi gradativamente substituída por outras atividades. Como exemplo, a banha que é um dos subprodutos da suinocultura, e que foi substituída por óleos vegetais. Neste período também os excedentes eram vendidos ou trocados, como por exemplo, galinhas e ovos, os quais eram trocados no comércio local (bolichos) por suprimentos que a propriedade não produzia, como açúcar, sal entre outros.

Uma curiosidade relatada pela entrevistada do distrito de Esquina Gaúcha foi que em 1948 já havia o plantio de fumo para a venda no qual não era utilizado nenhum produto químico. No ano de 1950 ocorreu uma safra muito produtiva de feijão e a partir deste ocorrido muitas propriedades começaram a cultivar e comercializar este produto. A partir do processo de revolução verde houve a extinção da venda do porco "tipo banha", sendo assim muitas propriedades passaram a se dedicar a atividades mais especializadas como a bovinocultura de leite, suinocultura, avicultura e produção de grãos para o comércio. Algumas propriedades utilizavam a soja e o milho produzidos para o consumo na propriedade para alimentação dos porcos e outros animais, no entanto algumas propriedades realizavam a venda do milho e da soja no comércio local, no qual obtinham uma das principais rendas no ano. Segundo Mantelli (2006):

Até a década de setenta, a produção suína era praticada de forma rudimentar, com o objetivo de fornecer carne e derivados para subsistência familiar. A implantação de várias indústrias de processamento (frigoríficos) incentivou o melhoramento da criação, que passou a ser orientada com base em uma tecnologia mais avançada e dirigida para a produção comercial.

Com relação à área destinada à produção de alimentos (subsistência familiar), observou-se uma diminuição drástica ao longo do tempo nas propriedades rurais. Segundo dados obtidos na pesquisa, no passado a área das propriedades destinada à produção de alimentos variava de 1,5 a 10 hectares. Atualmente, observa-se que a área é inferior a 0,5 hectare, chegando em algumas propriedades a ter apenas 0,25 hectares para a produção de alimentos. Essa diminuição está relacionada a diversos fatores, dentre os quais se destaca o êxodo rural, pois na maioria das propriedades os filhos foram para as cidades embora, ocorrendo uma diminuição na mão de obra familiar. Segundo Schneider (1995), a articulação da indústria com a agricultura familiar gerou não somente transformações nas atividades agrícolas dos pequenos agricultores, sobretudo mudanças ocasionadas no processo de produção, como também levou uma parcela significativa da força de trabalho das famílias rurais ao assalariamento nas fábricas dos grandes centros urbanos. Ainda, segundo Schneider \& Fialho (2000), pode-se observar nos últimos anos, uma diminuição das famílias ocupadas nas atividades agrícolas. Desta forma, a seletividade do processo de modernização da agricultura e as distorções sociais daí emergentes, como a expulsão de milhares de pequenos agricultores do campo, alteraram, sobremaneira, o modo de vida das populações rurais gaúchas e a própria geografia agrária (Schneider \& Fialho 2000).

Observa-se atualmente, que na maior parte das propriedades estudadas as pessoas que residem apresentam uma idade avançada, sendo este um entrave para o desenvolvimento das atividades agrícolas. Esse aspecto émuito importante na produção de alimentos para subsistência, pois necessita de muita mão de obra, tendo em vista que é pouco tecnificada. Conforme Reinehr (2015), as principais dificuldades das famílias produtora de alimentos são problemas de saúde, falta de mão de obra e à distância dos filhos, muitos na cidade, frutos do êxodo rural. 
Outro fator relevante foi a especialização das propriedades em atividades como a bovinocultura de leite e suinocultura, e assim não havendo possibilidade de tempo para produzir alimentos, mesmo os de subsistência familiar. Também se observou que nos últimos anos, o cultivo de grandes monoculturas, ocasionou o surgimento de várias doenças reduzindo a produtividade dos cultivos. Um exemplo é o feijão e o arroz, os quais tem sofrido com o surgimento de doenças, insetos e pássaros.

De acordo Gimenez et al. (2006), cultivos geneticamente uniformes da revolução verde também mostraram ser mais suscetíveis a pragas e doenças. Para proteger esses cultivos, tem sido realizada intensa aplicação de pesticidas cada vez menos efetivos e menos seletivos, dispersando-os na biosfera e provocando danos ambientais e humanos. Segundo Gimenez et al. (2006), o efeito global da revolução verde é a perda da fertilidade natural do solo, o aumento de danos provocados por pragas, a seca dos aquíferos e a redução da agrobiodiversidade.

Segundo Carvalho Filho (1995), a revolução verde provocou expressivos e positivos resultados nos campos da produção e da agro industrialização, resultando na mudança do padrão extensivo tradicional para um novo padrão intensivo, no qual o rendimento (produtividade da área) tornou-se a principal fonte de crescimento, desta forma o preço dos produtos alimentícios teve uma queda. Ainda, conforme os resultados das entrevistas, o mercado alimentício oferece aos consumidores produtos com baixo valor agregado, neste sentido muitos agricultores entendem ser mais viável financeiramente comprar alimentos do que produzir em suas propriedades. Enfim, constatou-se que a diminuição da área destinada a produção de alimentos está relacionada a fatores sociais e econômico, estando de acordo com o que foi proposto por Mantelli (2006):

Uma das consequências mais acentuadas foi a redução na produção de alimentos, pois à medida que o governo passou a privilegiar produtos como a soja, outros, destinados ao consumo alimentar da população, passaram a ser desprezados, não somente pelos agricultores detentores das maiores propriedades, mas, também, pelos caracterizados como pequenos agricultores familiares, na tentativa de tornar a sua unidade mais rentável. A redução da produção alimentar se fez sentir, principalmente, pela redução da área cultivada com mandioca (58\%), feijão $(48 \%)$ e milho $(32 \%)$.
A mudança ocorrida na produção de alimentos interferiu nos hábitos alimentares das pessoas residentes na propriedade, pois estas passaram a comprar alimentos nos supermercados, acreditando ser mais viável; no entanto não sabem a procedência e o manejo adotado para sua produção, o que ocasiona uma insegurança alimentar e nutricional, além de colocar em risco a soberania alimentar. Segundo Figueirêdo et al. (2015), hoje as comunidades rurais apresentam elevada dependência de compra de alimentos supermercados. Segundo o mesmo autor, os habitantes destas comunidades contribuem diretamente para a substituição dos alimentos produzidos localmente por produtos processados e industrializados. Além disso, muitos alimentos que eram consumidos antigamente hoje estão sendo substituído por produtos industrializados.

Durante o estudo foi observado que antes muitas propriedades industrializavam os próprios alimentos como: chimia de tacho, bolacha, cuca, derivados de carnes, entre outros. Desta forma, o abandono do alimento local e a aderência aos alimentos industrializados, na maioria das vezes ricos em açúcares e gorduras põem em risco a saúde humana (Figueirêdo et al. 2015). Para França et al. (2012) na contemporaneidade, a alimentação é caracterizada pelo estilo de vida moderno, marcada pela escassez de tempo para preparo e consumo de alimentos, o que leva à emergência de alimentos do tipo fast food, que emprega técnicas de conservação e preparo, agregando tempo e trabalho.

Portanto, constatou-se que ocorreu diminuição nas variedades destinadas à produção de alimentos, pois com o atual sistema agrário predominante muitas propriedades passaram a se dedicar ao cultivo das monoculturas. De acordo com Gimenez et al. (2006), sistemas agrícolas criados pela Revolução Verde são completamente dependentes de poucas variedades, desta forma a diversidade agrícola tem sido erodida enquanto a monocultura tem predominado no meio rural do Rio Grande do Sul e do Brasil, causando um alarmante esvaziamento demográfico do campo.

\section{Instituições públicas}

Conforme as informações obtidas através dos formulários aplicados nas entidades do município, observou-se coerência entre as informações obtidas no escritório municipal da EMATER-RS com os dados obtidos na secretaria municipal de agricultura. Um dos pontos avaliados foi o número de propriedades rurais 
e a área destinada nestas para a produção de alimentos para subsistência familiar. Como resultados observouse que atualmente o município de Crissiumal possui aproximadamente 2.400 propriedades rurais, no entanto este número é menor se comparado aos números de anos anteriores. De acordo com Machado (2001) no censo agropecuário 1995-1996, Crissiumal possuía 2.707 propriedades, sendo assim observa-se que em 21 anos houve uma diminuição de 307 propriedades em média.

Neste mesmo contexto, observou-se também uma diminuição no número dos integrantes das famílias rurais, sendo que nos anos de 1980 as propriedades possuíam em média seis pessoas, porém, atualmente, em média, residem em cada propriedade 3,5 pessoas. Essa diminuição do número de integrantes e de propriedades se deve possivelmente ao processo da revolução verde, a qual excluiu vários agricultores do campo, desta forma contribuindo para o êxodo rural. Além do que, o número de filhos por casais também diminuiu consideravelmente nos últimos anos. Essa constatação está de acordo com Abramovay (1998, p.4):

A cada década, mais de um terço da população residente no meio rural no início do período migrava em direção às cidades. Durante os anos 1980 foram mais de 12 milhões de pessoas e na primeira metade da década de 1990 , o êxodo já atingiu 5,6 milhões de indivíduos. Com a manutenção deste ritmo até o final da década teríamos a migração de $29,3 \%$ da população residente.

Ainda, segundo Oliveira et al (2011):

Pode-se inferir que os efeitos negativos do êxodo rural são relativamente preocupantes, por apresentarem influência direta sobre o meio natural, no que condiz a destruição de áreas de preservação para o desenvolvimento do latifúndio, e também sobre o meio social, destruindo a cultura tradicionalista do povo migrante, bem como, o aumento das grandes concentrações urbanas, causadoras de catástrofes incalculáveis em episódios diversificados em várias partes do mundo.

Outro fator que contribui para o êxodo rural no munícipio foi a utilização de máquinas, ou seja, adoção de novo sistema agrícola baseado na tecnologia. Conforme Machado (2001), a inadequação tecnológica é também um dos fatores que tem aumentado o êxodo rural em Crissiumal, pois é poupadora de mão-de-obra. Com estes equipamentos mecânicos, as práticas agrícolas são efetuadas em um tempo muito menor que o realizado manualmente. Em algumas práticas, um equipamento substitui o trabalho de mais de 15 homens (Machado, 2001). Ainda, assim segundo Machado (2001), no final da década de 1960, Crissiumal passa a sofrer um processo de êxodo rural expressivo, incentivado por um novo sistema agrícola baseado na tecnologia.

Com o presente trabalho, observou-se também que ocorreu uma diminuição no número de propriedades familiares. No entanto, houve uma tendência para o aumento da área das propriedades atuais, pois muitos agricultores compraram as propriedades vizinhas, os quais deixaram a região migrando para grandes centros, em busca de melhores condições de vida, pois sofriam com os impactos causados pela revolução verde, como já discutido anteriormente. Verificou-se também um aumento na concentração das terras no município de Crissiumal. Até 1970 era insignificante o número de estabelecimentos agropecuários com mais de 100 ha de área, porém, na década seguinte (1980) esses já somavam um total de 18. O número de estabelecimentos com 50 a 100 ha também aumenta e diminuem os estabelecimentos com área entre 10 a 20 ha, ou seja, há uma elevação da concentração das terras na medida em que os produtores mais capitalizados passam a adquirir áreas dos pequenos produtores (Machado, 2001).

Como já discutido anteriormente, atualmente o número de integrantes por propriedade é de apenas 3,5 pessoas, pois muitos jovens do campo migraram para centros urbanos em busca de novo estilo de vida, em decorrência que não havia incentivo nas décadas de 80 e 90 e início dos anos 2000 para pequenos agricultores. De acordo com Machado (2001), as políticas de estímulo à modernização não atingiram as pequenas unidades agrícolas, especialmente as que se dedicavam à produção de gêneros alimentícios de primeira necessidade. Dessa forma, ocorreu uma diminuição da mão de obra familiar das propriedades o que ocasionou consequentemente na redução na área destinada a produção de alimentos para subsistência familiar, pois as propriedades apresentavam número menor de integrantes e dispunha vão de menos força de trabalho.

Verificou-se que antes dos anos 80 a área destinada para a cultura da mandioca era em média de 1.200 hectares, porém nos dias atuais a área destinada para essa cultura é de aproximadamente 500 hectares, ou seja, a cultura perdeu espaço nas propriedades rurais para culturas 
de grãos como a soja que exigem menor mão de obra dos agricultores e, além disso, trazem maior retorno econômico que as culturas anteriormente cultivadas. De acordo com Machado (2001), os preços das commodites são relativamente mais favoráveis em relação às culturas tradicionais, pois, são produtos de exportação. Dessa forma, as culturas "modernas têm uma lucratividade maior que as tradicionais" (Machado, 2001, p.66).

Outro fator que pode estar associado às mudanças nos sistemas de produção é o número de fillhos por família na região, visto que ao longo das últimas décadas o número de filhos tem reduzido consideravelmente. Esta afirmação estaria de acordo com Camarano \& Abramovay (1999) que destacam que a redução da importância da população rural deve-se, fundamentalmente, aos movimentos migratórios. Mais recentemente, a queda de fecundidade rural contribuiu também para esta redução

No presente trabalho, analisou-se também qual era o manejo adotado pelos agricultores para a produção de alimentos, antes do efeito da revolução verde no município. Segundo as informações obtidas profissionais das instituições públicas no passado o manejo adotado nas propriedades era o convencional, sem a utilização de adubos químicos e agrotóxicos. A maioria das propriedades utilizava tração animal para o preparo do solo e para o plantio as sementes utilizadas eram crioulas, as quais não eram tradadas com produtos químicos. De acordo com Machado (2001), a técnica que era utilizada na ocupação das "colônias velhas", foi utilizada aqui pelos agricultores pioneiros quando chegaram ao município. Esta consistia na derrubada da vegetação com o auxílio de foice, machado e serrotes. Após a queima do material sobre o solo, era feita a semeadura, principalmente de milho e feijão ou plantio de ramas de mandioca na camada de cinzas com o auxílio de paus (ou saraquás). Naquela época se utilizava na maioria das propriedades o uso de consórcio de plantas ou policultivos que consiste em utilizar duas ou mais culturas diferentes em uma mesma área, afim de otimizar a área. Até os anos de 1980 o principal consórcio de plantas encontrado no município era de milho com soja. Enfim está prática apresenta inúmeras vantagens em relação aos monocultivos. Segundo Altieri (2002), dentre as principais vantagens do consórcio de plantas, pode-se destacar o aumento da eficiência do uso da terra, já que o consórcio normalmente apresenta uma produção agrícola maior do que as monoculturas e a menor frequência de pragas e doenças.

Com a revolução verde começou-se a utilizar produtos químicos nas lavouras a fim de aumentar a produtividade. Segundo dados obtidos, a partir de 1985 o processo da revolução verde transformou as formas de manejo adotadas pelos agricultores e a partir de então se extinguiu o consorcio de plantas nas propriedades, pois começou se a dedicar-se ao plantio de apenas uma cultura de interesse, a soja (Schneider \& Fialho 2000). Segundo os autores, a introdução da soja como principal produto comercial da lavoura gaúcha marca uma nova fase de desenvolvimento da economia agrária sul-rio-grandense.

Este novo modelo de agricultura após o processo da revolução verde, de acordo com Machado (2001), aumentou os custos de produção e intensificou as perdas de fertilidade dos solos. Em decorrência das mudanças na agricultura, verificou-se também que ocorreu uma mudança nos alimentos para subsistência produzidos pelos agricultores familiares do município de Crissiumal. Antigamente, antes da década de 90 as principais espécies cultivadas para o consumo familiar eram: feijão, batatadoce, batata inglesa, cebolas (as quais era amarradas para evitar fungos), milho pipoca crioulo, erva-mate, amendoim, alho, arroz sequeiro, milho, trigo, soja, vários tipos de hortaliças, entre outros. De acordo com Machado (2001), os agricultores produziam grande diversidade de alimentos, os quais se destinavam para a subsistência das famílias e alimentação dos animais na propriedade. Esta grande diversidade de culturas, está relacionada ao processo de colonização que o município passou, pois, os colonizadores introduziram novas culturas e formas de cultivo.

De acordo com Machado (2001, p.54),

Além das culturas de milho, feijão e mandioca (bianual), introduziram-se as seguintes culturas de verão: fumo, arroz, abóbora, tubérculos de batata inglesa e batata doce e cana de açúcar (bianual); e o trigo como cultura de inverno. Para o primeiro cultivo nas áreas novas, utilizavase, principalmente, uma parcela de milho consorciado com feijão e outra com fumo. No inverno, introduzia-se o trigo e no próximo verão voltava-se com as mesmas culturas ou com parcelas de mandioca consorciada com milho e feijão, cana de açúcar, abóbora consorciada com milho e mandioca, batata doce e batata inglesa. 
Atualmente são produzidos apenas alimentos de consumo primário, como hortaliças, mandioca e batatadoce. Desta forma, ocorreu uma diminuição no número de espécies cultivadas para o consumo familiar, sendo que essa redução se deve ao fato de muitas propriedades terem se especializado em algumas atividades agrícolas, tais como: suinocultura, bovinocultura de leite, avicultura e ao cultivo de monoculturas como soja, milho e trigo. Ainda, as variedades de hortaliças produzidas e consumidas são em menor número de comparadas ao que era consumido a cerca de 30 anos atrás.

De maneira geral, ao final da década de 1970, as transformações ocasionadas pela difusão da soja e pela modernização tecnológica da agricultura revelaramse particularmente intensas na região Noroeste do estado do Rio Grande do Sul. Em razão disso, um grande contingente de colonos viu-se forçado a abandonar suas atividades rurais e buscar outras alternativas, em face da impossibilidade de incorporação dessas novas tecnologias e de sua adequação ao padrão produtivo que passava a vigorar (Schneider \& Fialho 2000).

Desta forma, tem-se observado que o cultivo de soja e trigo principalmente, por não permitirem uma renda satisfatória a estes agricultores, tem incitado os produtores locais a buscarem outras atividades econômicas como a produção de leite, o cultivo do fumo, a criação de suínos (Machado, 2001). Ainda, com o passar dos anos um número cada vez mais alarmante de pessoas vem abandonando o campo.

Diante disso, a partir da década de 90 surgiu a necessidade de implantação de políticas agrícolas voltadas para o pequeno agricultor (Schwanke \& Pohl, 2007). Sendo assim, com o passar do tempo o campo se modernizou e profissionalizou. Esse aperfeiçoamento dos produtores rurais se deu devido a criação de programas governamentais de incentivo a agricultura familiar. A facilidade de acesso ao crédito, que tinha como finalidade estimular os investimentos rurais, nessa época, introduziu muitos equipamentos direcionados para a produção de alimentos

Através de entidades foram disponibilizados diversos cursos de treinamento aos agricultores, e juntamente com o auxílio rotineiro de técnicos capacitados, fizeram com que a agricultura familiar passasse de uma economia solidária para um regime de vendas com qualidade. Guilhoto et al. (2007) conclui que a agricultura familiar tem peso significativo para a riqueza do País, que é representativo e não perdeu sua força nos últimos anos. Dessa forma a agricultura familiar é responsável pela produção de grande parte do alimento produzido no Brasil (cerca de 87\%), contribuindo para o desenvolvimento social e econômico do país. Mas o processo de modernização da produção rural, muitas vezes, beneficia mais a produção patronal do que a familiar[...]".

A partir dos anos de 1995 vários programas de incentivo a agricultura familiar foram criados, como o programa de financiamento de aquisição de terras (banco da terra) os quais incentivaram os agricultores a permanecer no meio rural. Ainda, neste contexto em 1995, foi criado o Programa Nacional de Fortalecimento da Agricultura Familiar (Pronaf). Segundo Antão \& Campanholo (2011):

O Pronaf é um meio de viabilização para a implantação, ampliação e modernização da infraestrutura produtiva e social no meio rural, através do auxílio financeiro prestado aos pequenos produtores rurais que são responsáveis por $38 \%$ do valor bruto da produção nacional de alimentos.

$\mathrm{Na}$ década de 2000, houve incentivos e financiamentos direcionados para a produção comercial de suínos e para o aumento e fortalecimento da cadeia leiteira. Os programas governamentais federais, estaduais e municipais impulsionaram a criação das agroindústrias familiares do município de Crissiumal em meados de 2005, o que contribuiu naquela época, para o aumento da produtividade e a melhoria do padrão de vida da população rural. Possivelmente, devido às políticas públicas adotadas para a agricultura familiar no município, inúmeros produtores permaneceram na agricultura, fazendo com que a zona rural apresentasse maior população em relação aos habitantes da zona urbana. De acordo com Barbosa (2010), em 2009, o munícipio apresentava $45,14 \%$ da população na zona urbana e 54,86\% da população na zona rural. Desta forma, estes incentivos nas pequenas propriedades contribuíram para o aproveitamento da mão de obra local, fazendo assim com que muitos dos jovens permanecessem na agricultura e reestabelecessem a economia da propriedade diminuindo o êxodo rural do município. Ainda, de acordo com Schwanke \& Pohl (2007), no município de Crissiumal direcionou-se uma política para agricultura familiar, que tem desempenhado um papel extremamente importante 
na produção de alimentos, para abastecimento do mercado interno, e na geração de oportunidades de trabalho e renda no campo.

Conforme Barbosa (2010), a distribuição da população rural e urbana de 1980 a 2009 na Região Celeiro, sofreu evolução. Na década de 80 , cerca de $67 \%$ da população residia no campo e $33 \%$ no meio urbano. Essa característica se altera a partir de 2000 , quando passa a apresentar índices equivalentes (49\% residindo na zona rural e $51 \%$ em área urbana). Em 2009, porém, os dados revelam uma tendência à inversão, apresentando população urbana $58,31 \%$, e população da zona rural sendo de $41,69 \%$, sendo assim a população urbana na maioria dos munícipios da região é superior à rural, seguindo a tendência de outros munícipios brasileiros. No entanto, alguns munícipios da região que investiram em políticas públicas de incentivo à agricultura familiar e que possuem relevo acidentado o que dificulta mecanização das lavouras, ainda apresentam população rural superior que a urbana, como caso do munícipio de Crissiumal onde de acordo com Barbosa (2010) 54,86\% da população vive na área rural e 45,14\% na área urbana. Outros munícipios da região como Três Passos e Santo Augusto apresentam percentagem de pessoas vivendo no meio rural muito baixa, sendo de $19,81 \%$ e $18,44 \%$ respectivamente.

Barbosa (2010) destaca que na Região Celeiro a elevação da população na zona urbana pode ser explicada pela falta de investimentos em infraestrutura nas áreas rurais, poucos recursos destinados a programas de qualificação de mão de obra, adoção de sistemas de produção mecanizada. Aliado a isto, destaca-se as constantes frustrações de safras, que afetam a produção agrícola. Essa situação vem provocando a migração da população, principalmente de jovens, que buscam alternativas de trabalho em centros maiores e mais industrializados, bem como o suprimento de necessidades básicas facilitadoras da vida moderna. Ainda, de acordo com Barbosa (2010), pode-se destacar o acesso à infraestrutura, equipamentos e serviços públicos e instituições educacionais que favorecem a qualidade de vida. No entanto, ressalta-se que municípios da região que investiram em políticas de incentivo à agricultura familiar, ou seja, que incentivaram a agricultura, como os munícipios de Crissiumal, Tiradentes do Sul, Esperança do Sul, Vista Gaúcha, dentre outros, apresentam polução rural superior a urbana. $O$ crédito rural tem enorme importância em relação à economia rural e à necessidade do amparo ao produtor, para possibilitar um melhor investimento na lavoura e uma melhor qualidade de vida das famílias rurais. De acordo com Antão \& Campanholo (2011), o crédito rural é um instrumento que proporciona aos produtores rurais a oportunidade de desenvolverem economicamente, de aprimorarem suas técnicas de produção, melhorar o plantio, gerando uma produção mais eficaz e mais rentável. O fácil acesso ao crédito permitiu a aquisição de máquinas e insumos agrícolas. Neste contexto, acontece o ingresso dos produtores rurais, independentemente do tamanho do estabelecimento, na produção modernizada e totalmente integrada no mercado. Esta mudança deu-se de forma extremamente rápida e teve sua consolidação na década de setenta na região. Em alguns casos, esse fácil acesso ao crédito aliado a má administração da propriedade, fez com que alguns produtores familiares decretassem falência, $o$ que acarretou em um período mais prolongado de reestabelecimento das mesmas.

As mudanças ocorridas na produção de alimentos influenciaram de forma negativa nos hábitos alimentares das famílias rurais, pois houve uma diminuição na produção destinada ao consumo familiar, uma vez que área destina à produção de alimentos para subsistência diminui nos últimos anos. Este fato desencadeou a perda da diversidade de produtos produzidos nas propriedades familiares (erosão alimentar), sendo que isso ocasionou a extinção das variedades crioulas destacando o milho crioulo, variedades de arroz sequeiro e feijão, pois antes destas mudanças ocorridas existiam várias variedades destas culturas. Segundo Santos et al. (2012), com a utilização de novas tecnologias, foi necessário o desmatamento de áreas de cobertura natural, levando à devastação de florestas e de campos nativos, ao empobrecimento da biodiversidade e da perda de recursos genéticos.

A diversidade de cultura foi gradativamente substituída por poucas cultivares e estas em sua maioria transgênicas. Uma vez que os transgênicos são introduzidos em uma região dominada por pequenos produtores, todos os agricultores eventualmente terão que adotar, ou pagar altas taxas para as companhias de sementes por "roubar" o material genético que involuntariamente atravessa os limites de seus campos (Gimenez et al., 2006). Além disso segundo o autor, sob estas circunstâncias, a dependência dos agricultores levará ao enriquecimento das companhias transnacionais 
que comercializam sementes transgênicas, fertilizantes e herbicidas, mas não acabará com a fome. Desta forma, estas mudanças ocorridas na produção de alimentos colocam em risco a soberania e a segurança alimentar das famílias rurais e urbanas, pois se perdeu grande parte da diversidade de espécies de plantas cultivadas. As mudanças ocorridas na produção de alimentos fizeram com que os agricultores familiares, se tornassem dependentes das grandes indústrias, pois, estas produzem sementes que não penduram por muito tempo, assim impedindo que o produtor possa guardar as sementes, muitos ainda necessitam de subsídios para implantação das lavouras, sendo assim os agricultores são altamente dependes da indústria. De acordo com Machado (2001), o agricultor tornou-se dependente de recursos e instituições de créditos sendo assim houve aumento dos custos de produção e se intensificaram as perdas de fertilidade dos solos, dessa forma as grandes indústrias têm autonomia para aumentar o preço de seus produtos, pois este é transferido a seus consumidores, representado pelos produtores. Além disso, o desequilíbrio causado por esse modelo de produção agrícola faz com que haja grande incidência de pragas e doenças, sendo necessárias grandes quantidades de produtos químicos a fím de manter a produção, ou seja, é necessário utilizar os pacotes tecnológicos destas empresas. Santos (1988) afirma que o uso intensivo e inadequado de agrotóxicos ainda trouxe um processo de resistência de pragas, ervas infestantes e doenças (até 1958, eram conhecidas 193 pragas no Brasil; em 1976, o número total de pragas conhecidas na agricultura era 593). Sendo assim, observa-se que é crescente o descobrimento de doenças e pragas cada ano agrícola.

Verificou-se que utilização dos meios de comunicação como televisão apresentou-se como fator importante para que ocorresse as mudanças nos hábitos alimentares das famílias rurais, pois influenciaram as pessoas a consumir produtos industrializados. Segundo Belink \& Siliprandi (2010), as empresas agroalimentares nos induzem, por meio da publicidade direta e indireta, a abandonar velhos hábitos e a incorporar o consumo de determinados produtos que antes não faziam parte de nossa dieta. Desta forma, os resultados dessas mudanças na alimentação, do ponto de vista da saúde pública, são bastante conhecidos: a falta de uma alimentação balanceada e diversiûcada somado à falta de exercícios físicos, induz ao aumento da incidência de sobrepeso, de doenças não transmissíveis como diabetes, hipertensão, cânceres, atrites, cardiopatias e tantas outras doenças causadas por práticas alimentares inadequadas e relacionadas com o estilo de vida moderno (Belink \& Siliprandi, 2010).

Portanto, as novas práticas agrícolas associadas ao cultivo de poucas espécies estão comprometendo os sistemas de produção e a quantidade e qualidade dos alimentos produzidos.

\section{CONCLUSÕES}

Verifica-se que ocorreram grandes mudanças na produção de alimentos na agricultura familiar do município de Crissiumal nas últimas décadas, sendo que as principais mudanças ocorreram a partir década de 80 .

Constatou-se que houve diminuição significativa da área destinada à produção de alimentos para o consumo familiar, devido à diminuição do número de integrantes das famílias rurais, acarretando na redução da mão de obra necessárias para a produção de alimentos. Ainda, constata-se que o número de variedades cultivadas para alimentação das famílias rurais entrevistadas é inferior se comparado aos anos anteriores, e desta forma, os agricultores se tornaram muito dependentes de alimentos oferecidos pela indústria, influenciando nos hábitos alimentares da população rural.

\section{LITERATURA CITADA}

ABRAMOVAY, R. Agricultura familiar e desenvolvimento territorial. Reforma agrária, v. 28, n. 1, p. 2, 1998.

ALTIERI, M. Agroecologia: bases científicas para uma agricultura sustentável. Guaíba: Agropecuária, 2002. 592p.

ANTÃO, R.A. de S.; CAMPANHOLO, T. O crédito rural no contexto do desenvolvimento econômico e social. Revista da Católica, v. 3, n. 5, p. 1$12,2011$.

BARBOSA, F. et al. Plano Estratégico de Desenvolvimento da Região CeleiroRS. Ijuí: Ed. Unijuí, 2010. 76 p.

BELIK, W.; SILIPRANDI, E. Hábitos Alimentares, Segurança e Soberania Alimentar. VILARTA, R.; GUSTAVO, L.; GUTIERREZ, G.L.; MONTERIO, M.I. (Orgs.). Qualidade de Vida: Evolução dos Conceitos e Práticas no Século XXI, v. 1, p. 187-196, 2010. 
CARVALHO FILHO, J.J. A produção de alimentos e o problema da segurança alimentar. Estudos Avançados, v. 9, n. 24, p. 173-193, 1995.

CASTRO, A.C.Q. Impactos regionais de mudanças tecnológicas na agropecuária: Região Celeiro do Rio Grande do Sul. Porto Alegre, 2001. 194p. Dissertação (Mestrado em Economia Rural). Universidade Federal do Rio Grande do Sul, Porto Alegre, 2001. Disponível em: < http://

www.lume.ufrgs.br/handle/10183/1667> Acesso em: 07 de set. 2017.

CAMARANO, A.A.; ABRAMOVAY, R. Êxodo rural, envelhecimento e masculinização no Brasil: panorama dos últimos 50 anos. 1999. Disponível em: < http://repositorio.ipea.gov.br/handle/11058/2651> Acessado em: 07 de set. 2017

FIGUEIRÊDO R. et al. Mudanças de Hábitos Alimentares em comunidades Rurais do semiárido da Região Nordeste do Brasil. Interciencia, v. 40, n. 5, 2015.

FRANÇA, F.C.O. et al. Mudanças dos hábitos alimentares provocados pela industrialização eo impacto sobre a saúde do brasileiro. Anais do I Seminário Alimentação e Cultura na Bahia, v. 1, p. 1-7, 2012. Disponível em: < http:// www2.uefs.br:8081/cer/wp-content/uploads/

FRANCA_Fabiana.pdf $>$. Acesso em: 07 de set. 2017.

HOLT-GIMENEZ, E.; ALTIERI, M. A.; ROSSET, P. Posição Política de Food First no 12: Dez Razões pelas quais a Aliança por uma Nova Revolução Verde, promovida pelas Fundações Rockfeller e Bill \& Melinda Gates, não resolverá os problemas de pobreza e fome na África Subsaariana. 2006. Disponível em: < https:// s3.amazonaws.com/academia.edu.documents/ 30823160/PB12-10ReasonsPortuguese.pdf?AWS AccessKeyId=AKIAIWOWY YGZ2Y53UL3A\& Expires $=1520608164 \&$ Signature $=R X$

54IkTmeXgS023YxLMoPWzFVSw\%3D\&responsecontent-disposition $=$ inline $\% 3 \mathrm{~B} \% 20$ filename $\%$ 3DPosicao_Politica_de_Food_First_no_12_Dez.pdf $>$. Acesso em: 07 de set. 2017.

GUilhoto, J.J.M. et al. A importância da agricultura familiar no Brasil e em seus estados. Brasília: NEAD, 2007.
MANTELLI, J. O setor agrário da região noroeste do Rio Grande do Sul. 2006. Disponível em: < http://repositorio.furg.br/handle/ 1/1094> Acesso em: 28 de set. 2017

MACHADO, R.T. Análise sócio econômica e perspectivas de Desenvolvimento para os produtores de Leite do município de Crissiumal - RS. 2001. 155p. Dissertação (Mestrado em Programa de pósgraduação em Desenvolvimento Rural) -

Universidade Federal do Rio Grande do Sul, Porto Alegre,2001.

OLIVEIRA, E. et al. Êxodo rural e sua problemática em relação ao meio ambiente e sociedade civil. In:

Anais I Seminário Internacional dos Espaços de Fronteira, III Seminário Regional sobre Território, Fronteira e Cultura e VII Expedição Geográfica da Unioeste: Espaços FronteiraTerritório e Ambiente, 14 a 17 setembro de 2011, Marechal Candido Rodon- Paraná. Disponível em: < http://cac-php.unioeste.br/eventos/ geofronteira/anais2011/Arquivos/Artigos/GESTAO/ Artigo75.pdf $>$ Acesso em: 28 de set. 2017.

OLIVEIRA, P. Notas sobre a História da Agricultura através do tempo. In: Projeto Tecnologias Alternativas - FASE, 1989. 39p.

PLETSCH, J.R. História de Crissiumal. Editor Colégios Salesiano- Dom Bosco. Santa Rosa - RS, 1997.

PRESSER, M.F. et al. O desenvolvimento do capitalismo na agricultura do Rio Grande do Sul: 1920-1975. 1978. Disponível em: < http://repositorio.unicamp.br/ bitstream/REPOSIP/285666/1/Presser_Mario Ferreira_M.pdf $>$ Acesso em: 28 de set. 2017.

REINEHR, C. Agricultura familiar: um estudo de caso sobre desenvolvimento sustentável e produtividade. 2015. 195p.

Dissertação (Mestrado Gestão e Desenvolvimento Regional) - Universidade Estadual do Oeste do Paraná, Francisco Beltrão, 2015.

SANTOS, R.F. et al. Análise crítica da interpretação neoclássica do processo de modernização da agricultura brasileira. Revista de Economía Política (Brasil), 1988. 
SANTOS, R.L. et al. Impactos socioeconômicos e ambientais causados pela modernização da agricultura brasileira. In: Anais da XXI Semana de Geografia da FAFIPA, 24 a 29 setembro de 2012, Paranavaí-Paraná. Disponível em: <http://www.fafipa.br/site/images/ stories/AnaisGeografia2012/ResExp03.pdf> Acesso em: 28 de set. 2017.

SCHALLENBERGER, E.; HARTMANN, H.R.

Nova terra, novos rumos: a

experiência de colonização e povoamento na Grande Santa Rosa.

Santa Rosa, RS; Barcellos Livreiro e Editor, 1981.

SCHNEIDER, S. As transformações recentes da agricultura familiar no Rio Grande do Sul: o caso da agricultura em tempo parcial. Ensaios FEE, v. 16, n. 1, p. 104-129, 1995.
SCHNEIDER, S.; FIALHO, M.A.V. Pobreza rural, desequilíbrios regionais e desenvolvimento agrário no Rio Grande do Sul. Teoria e Evidência Econômica, v. 8, n. 15, p. 117 $149,2000$.

SCHWANKE, T.M.L.; POHL, V.L.B. Da

Criciúma a Crissiumal. 1.ed. Três de Maio: SETREM, 2007.163p.

TRENNEPOHL, D.; 0MACAGNAN, R. Impactos ambientais da dinâmica de desenvolvimento da região noroeste colonial do Rio Grande do Sul.

Revista Brasileira de Gestão e Desenvolvimento Regional, v. 4, n. 1, 2008.

Recebido para publicação em 13/03/2018 e aprovado em 30/06/2018. 